\title{
Strengthening the existing connection of steel beams with a column
}

\author{
Przemysław Palacz ${ }^{1, *}$ and Izabela Major $^{1}$ \\ ${ }^{1}$ Czestochowa University of Technology, Faculty of Civil Engineering, Akademicka Street 3, 42-200 \\ Częstochowa, Poland
}

\begin{abstract}
The paper presents a solution that includes strengthening the connection of a support column with beams from both sides, placed in a vertical plane together with the pole. All the bar elements connected in the analyzed node were made of hot-rolled steel I-sections. Due to the need to increase the load on the joined beams to the pole, load-bearing capacity of the primary connection is lost, which necessitates the reinforcement of the existing connection. The analysis carried out in this paper shown exceeding the allowable stresses in the column web at the place of joining the beams. The calculations made in this paper showed the possibilities of restoring the safe operation of the connection node in question, by introducing elements increasing its load-bearing capacity. In addition to analytical calculations, numerical analysis was also performed using the ADINA program.
\end{abstract}

\section{Introduction}

In steel structures, bolted connections allow quick connection of structure elements during assembly on site. Correctly designed assembly contacts transfer loads from individual structure elements to the supporting elements ensuring safe exploitation of the object [1]. Bolted connections can be divided into shear connections where the force acts perpendicular to the axis of the connection and tension connections where the force acts parallel to the axis of the connection. In bolted connections of steel components of the structure bolts of class 4.6, 4.8, 5.6, 5.8, 6.8, 8.8 and 10.9 are used, depending on the category of connection. For category A overlapped joints (bearing type) and category D end-plate connections (non-preloaded) are use bolts from 4.6 to 10.9 class, while in category B and C overlapped joints (slip-resistant at serviceability limit state) and category E end-plate connections (preloaded) are use bolts for prestressing class 8.8 or 10.9 [2]. The type of structure connection adopted depends on the static node design as well as on the node layout resulting from the geometry of the connected structural elements. The correctness of the designed bolted connection determines the appropriate load transfer of the joined elements ensuring safe exploitation of the object [3].

The general rules of design of steel structure nodes are contained in part 8 in Eurocode 3 [4]. In steel connections, all elements ensuring load-bearing capacity of the connection should be checked. In the case of joining beams with a column (see [5]), check the load

*Corresponding author: przemyslaw.palacz@pcz.pl 
capacity of individual node elements such as: screws (tensile and shear), end plate (for bending), load capacity of the column web (in the compressed, shear and tension zone), column strips (for bending), beam (in the compressed and tension zone). For example, if the load capacity of the bolts is insufficient, then the number of bolts or the bolt class or diameter should be increased. However, if the column's web load capacity is insufficient, then reinforcement may be added, e.g. in the form of a welded overlay to the web or stiffeners welded on the beam's extension. For atypical nodes for which there are no standard calculation procedures, tests are carried out in the laboratory, comparing the results obtained in FEM-based programs (comp. [6, 7]) and analytical calculations to complement the standard dimensioning algorithms. The analysis of bolted connections was carried out by many researchers [8-12], these tests took place under various conditions, e.g. under the influence of temperature [13] as well as for various kind of connection, e.g. for connections used for fixation of glass facades [14]. The influence of high tensile bolts tightening torque on stress distribution in the bolted connection of rockfall barrier under impact load was also examined [15]. The authors of the paper [5] conducted analysis of the mechanical behavior of bolted beam-column connections with different structural forms, experimental studies including modelling of bolted T-stubs under cyclic loads were also conducted [16]. This article compares the analytical calculations of the bolted connection of double-sided beams connected to the column made according to the standard [4] with the results obtained in the ADINA program.

\section{Geometry of the analyzed bolt connection}

The analyzed bolted connection includes a column made of HEB 160 sections, which is connected with double-sided beams made of IPE 300 sections. (Fig. 1). The connection is statically loaded, while the connection has been designed as a bolted connection with a $20 \mathrm{~mm}$ thick, $160 \mathrm{~mm}$ wide and $390 \mathrm{~mm}$ high end plate. The column is made of S235 steel and the end plate and beams are made of S355 steel.

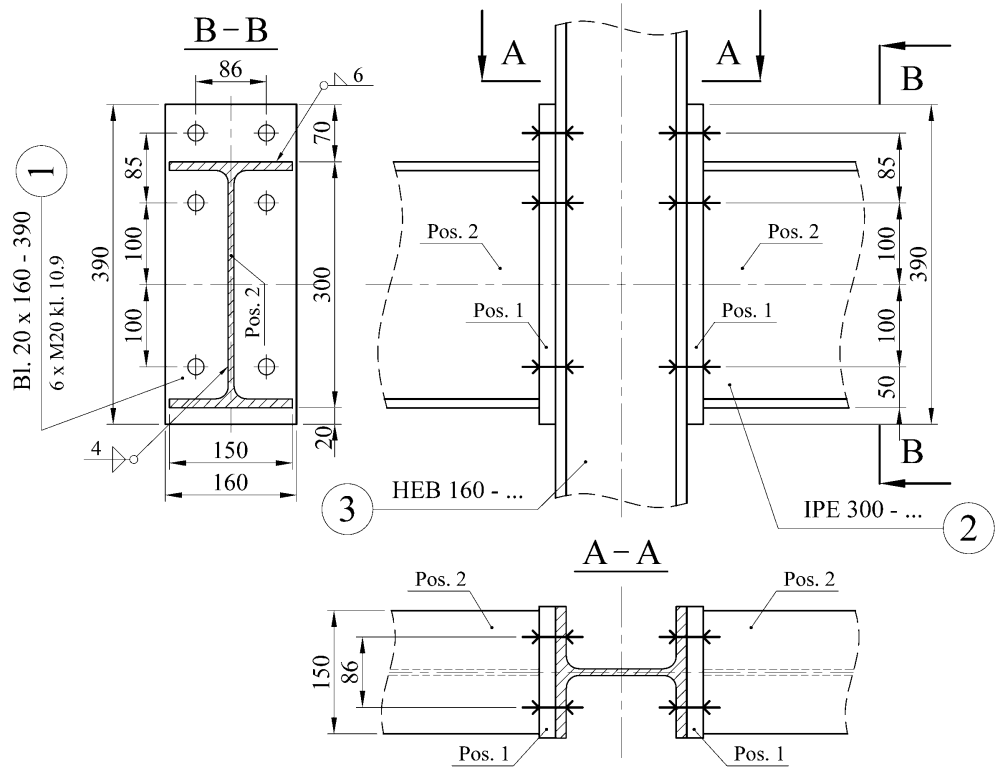

Fig. 1. The geometry of the analyzed bolt connection. 
In the analyzed example, it was assumed that the existing connection meets the strength conditions during the current operation, while due to the additional load on the ceiling and, as a consequence, beams, it should be checked how the increased load will affect the safety of the connection.

\section{Analytical and numerical analysis of the connection}

Calculations include the bearing capacity of a bolted connection of a column with beams, in which the load from the beam transferred to the column is in the connection axis. For each beam the cutting force is $140 \mathrm{kN}$, while the bending moment is $100 \mathrm{kNm}$ in the connection axis. Calculations were made on the basis of the Eurocode 3 [4]. In the case of bolted connections, the load capacity when bending a beam node with a column with a connection for plates and bolts is determined by the formula

$$
M_{j, R d}=\sum_{r} h_{r} F_{t r, R d}
$$

where

$F_{t r, R d}$ - effective load capacity of r-series bolts when stretching;

$h_{r} \quad$ - distance from the bolts of the $\mathrm{r}$ series to the center of compression;

$r \quad$ - bolt line number.

The load capacity of the connection to transfer the lateral force $V_{E d}$ is provided by bolts at the bottom of the node that do not participate in the transmission of stretching. Therefore, these bolts must be checked according to table 3.4 of the Eurocode 3 [4]

where

$$
V_{E d} \leq V_{R d}=n_{s} \cdot \min \left(F_{v, R d}, F_{b, R d}\right)
$$

$n_{s} \quad$ - is the number of bolts at the bottom of the node that are not involved in the transmission of stretching;

$F_{v, R d}$ - shear resistance per shear plane;

$F_{b, R d}$ - bolt bearing resistance.

When determining the effective load capacity of the first and second series of bolts, the load capacity of each element in the joint was calculated (column web load capacity, column belt load capacity, beam load capacity, end plate load capacity). The bearing capacity of series 1 and 2 was reduced due to the stretched web plate, as it proved to be the weakest element in the connection. The bearing capacity according to formula (1) was

$$
M_{j, R d}=0.32965 \mathrm{~m} \cdot 226.89 \mathrm{kN}+0.24465 \mathrm{~m} \cdot 74.10 \mathrm{kN}=92.92 \mathrm{kNm}
$$

Condition of load capacity of the joint when bending

$$
\frac{M_{E d}}{M_{j, R d}}=\frac{100 \mathrm{kNm}}{92.92 \mathrm{kNm}}=1.08>1
$$

Condition of shear load capacity

$$
\frac{V_{E d}}{n_{s} \cdot \min \left(F_{v, R d}, F_{b, R d}\right)}=\frac{140 \mathrm{kN}}{2 \cdot \min (98 \mathrm{kN}, 115.2 \mathrm{kN})}=\frac{140 \mathrm{kN}}{196 \mathrm{kN}}=0.71<1
$$

Calculations according to the Eurocode 3 [4] indicate that the connection does not meet the bending strength condition. The weakest element in the connection is the column web, therefore the connection should be reinforcement by adding stiffeners or a supplementary web plate. 

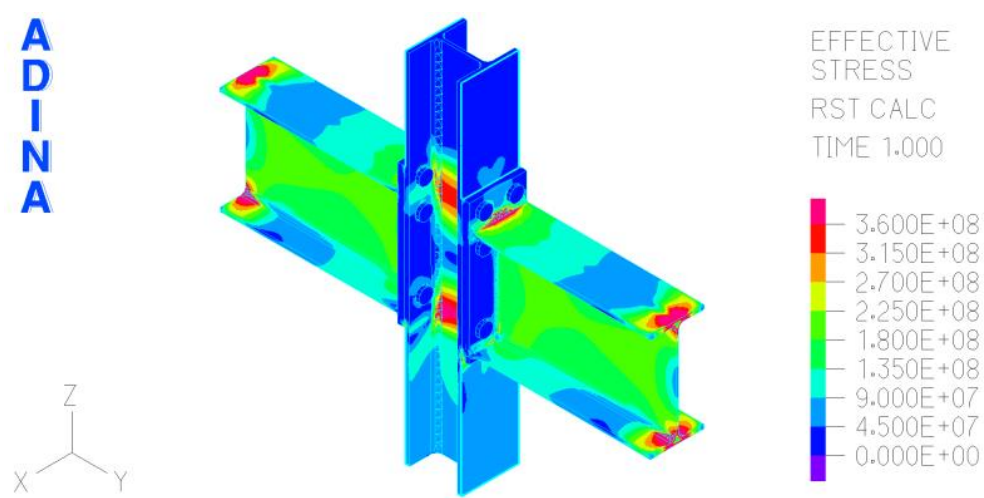

Fig. 2. Analysis of model stress in the ADINA program.

Model analysis in ADINA shows that the stress in the connection has exceeded the allowable stress values, which confirms that the connection is incorrect. Discretization of the area of the bolt connection was based on 10-node 3D Solid elements. Density of the grid for the bolt was assumed as $0.005 \mathrm{~m}$, whereas on the other elements, the density was limited to $0.01 \mathrm{~m}$. The analysis of the connection and stress distribution (Fig. 2) indicates that the column web is not able to transfer the load safely. Numerical analysis showed the need to strengthen the connection. In column and beam connections, the column's web is usually the weakest point, and the reinforcement of this element allows the load capacity of the remaining elements of the node to be used, thus increasing the load capacity of the entire connection.

\section{Reinforced connection}

\subsection{Reinforced of the bolt connection by column stiffeners}

The first variant of strengthening the connection is the use of horizontal stiffeners on the extension of the IPE 300 beam shelves (Fig. 3). The web stiffeners are made of $6 \mathrm{~mm}$ thick S235 steel welded with a double fillet weld $(a=4 \mathrm{~mm})$. The calculations were made analogously to the calculation of the connection without reinforcements, taking into account the web stiffeners according to the Eurocode 3 [4].

Load capacity, including web stiffeners according to formula (1)

$$
M_{j, R d}=0.32965 \mathrm{~m} \cdot 249.54 \mathrm{kN}+0.24465 \mathrm{~m} \cdot 249.54 \mathrm{kN}=143.31 \mathrm{kNm}
$$

Condition of load capacity of the joint when bending

$$
\frac{M_{E d}}{M_{j, R d}}=\frac{100 \mathrm{kNm}}{143.31 \mathrm{kNm}}=0.70<1
$$

Initial rotational stiffness according to Eurocode 3 [4]

where

$$
S_{j, \text { ini }}=\frac{E z_{e q}{ }^{2}}{\sum_{i} \frac{1}{k_{i}}}=\frac{2.1 \mathrm{e} 8 \frac{\mathrm{kN}}{\mathrm{m}^{2}} \cdot(0.2919 \mathrm{~m})^{2}}{\frac{1}{0.00594 \mathrm{~m}}}=106216.04 \frac{\mathrm{kNm}}{\mathrm{rad}}
$$

$z_{e q} \quad-$ is the equivalent lever arm;

$k_{i} \quad-$ is the stiffness coefficient representing component $i$ relative to bolt-row $r$. 


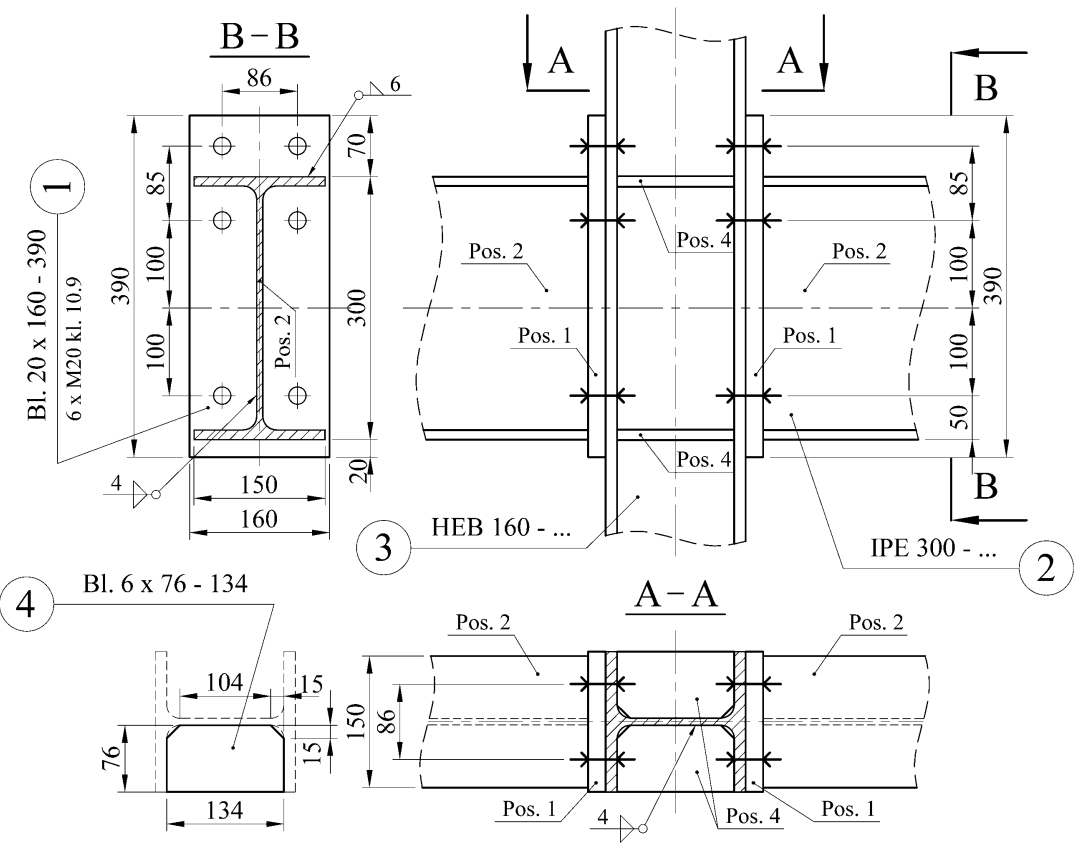

Fig. 3. Geometry of the analyzed bolted connection reinforced by web stiffeners.

Calculations according to the standard [4] indicate that the connection reinforced with horizontal ribs meets the bending strength condition. Checking the shear load condition is unnecessary because the ribs did not affect the shear load capacity.

\section{A
D
I
A}
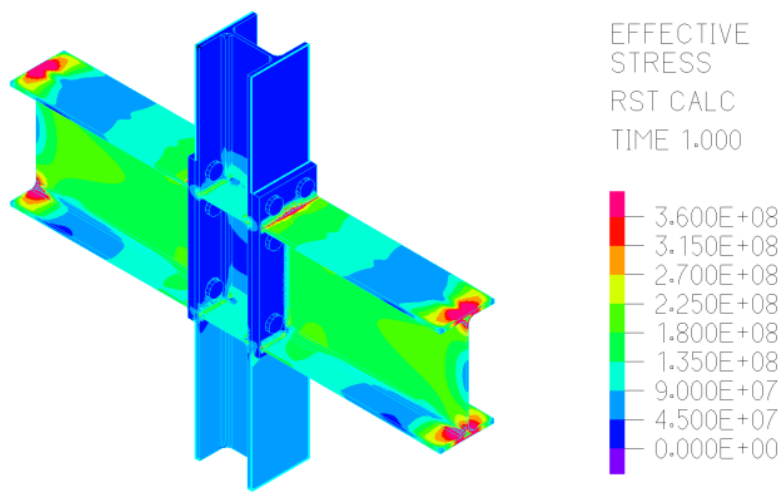

Fig. 4. Analysis stress of reinforcement model by flanges in the ADINA program.

Analysis of the model in ADINA shows that the stresses in the reinforced joint by web stiffeners did not exceed the allowable stress values, and the joint works correctly. Discretization of the area of the bolt connection was based on 10-node 3D Solid elements. Density of the grid for the bolt was assumed as $0.005 \mathrm{~m}$, whereas on the other elements, the density was limited to $0.01 \mathrm{~m}$. The analysis of the connection and stress distribution (Fig. 4) indicates that the stresses in the column web have significantly decreased compared to the unreinforced model, and the connection is able to safely transfer additional load. Analytical analysis according to the Eurocode 3 [4] and numerical analysis in the ADINA program 
showed that the proposed modification of the connection by welding the stiffeners will ensure the load capacity of the connection.

\subsection{Reinforcement of the bolt connection by means of a column web overlay}

The second variant of strengthening the connection is the use of a one-sided pad for the column web (Fig. 5). The overlay is made of S235 steel sheet $8 \mathrm{~mm}$ thick, $104 \mathrm{~mm}$ wide and $470 \mathrm{~mm}$ long, welded with a fillet weld $(a=5 \mathrm{~mm})$.

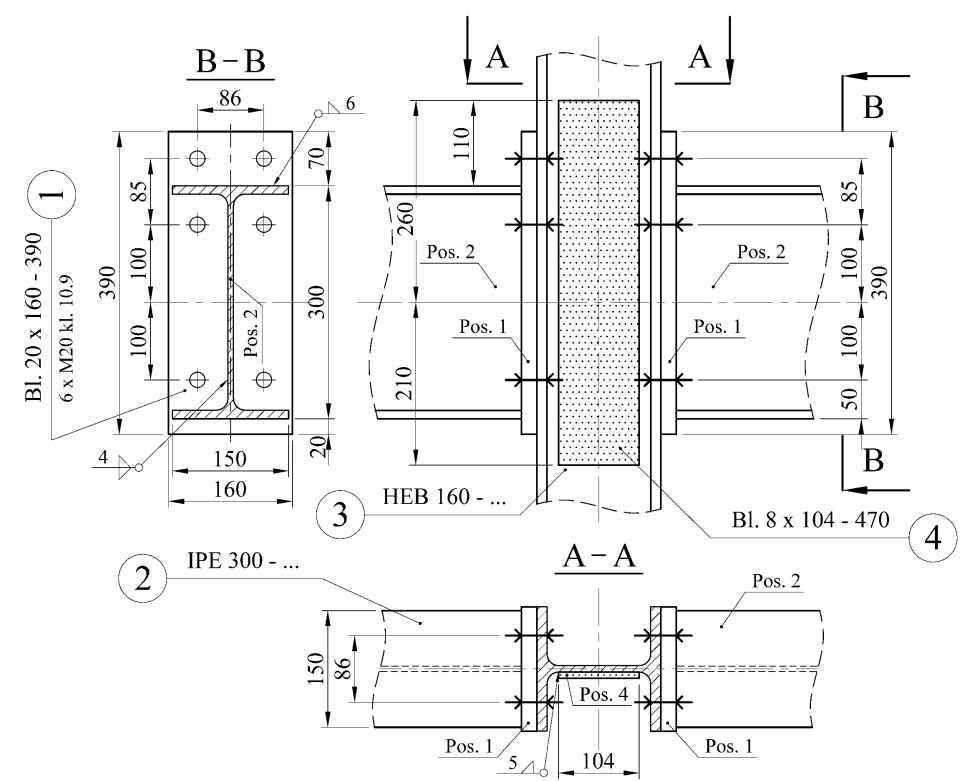

Fig. 5. Geometry of the analyzed bolt connection reinforced with an web overlay.

Load capacity considering the one-sided web overlay according to formula (1)

$$
M_{j, R d}=0.32965 \mathrm{~m} \cdot 226.89 \mathrm{kN}+0.24465 \mathrm{~m} \cdot 125.029 \mathrm{kN}=105.38 \mathrm{kNm}
$$

Condition of load capacity of the joint when bending

$$
\frac{M_{E d}}{M_{j, R d}}=\frac{100 \mathrm{kNm}}{105.38 \mathrm{kNm}}=0.95<1
$$

Initial rotational stiffness according to Eurocode 3 [4]

$$
S_{j, \text { ini }}=\frac{E z_{e q}{ }^{2}}{\sum_{i} \frac{1}{k_{i}}}=\frac{2.1 \mathrm{e} 8 \frac{\mathrm{kN}}{\mathrm{m}^{2}} \cdot(0.2919 \mathrm{~m})^{2}}{\frac{1}{0.01677 \mathrm{~m}}+\frac{1}{0.00604 \mathrm{~m}}}=78074.52 \frac{\mathrm{kNm}}{\mathrm{rad}}
$$

Calculations according to the Eurocode 3 [4] indicate that the connection reinforced by means of a welded pad to the web meets the condition of bending strength. Checking the shear load condition is unnecessary because the overlay has not affected the shear load capacity.

The analysis of the model in ADINA program shows that the stresses in the joint reinforced with the web overlay have not exceeded the allowable stress values, and the joint works correctly. Discretization of the area of the bolt connection was based on 10-node 3D Solid elements. Density of the grid for the bolt was assumed as $0.005 \mathrm{~m}$, whereas on the 
other elements, the density was limited to $0.01 \mathrm{~m}$. The analysis of the connection and stress distribution (Fig. 6) indicates that the stresses in the column web have significantly decreased compared to the unreinforced model, and the connection is able to safely transfer additional load. Analytical analysis according to the Eurocode 3 [4] and analysis numerical in the ADINA program showed that the proposed modification of the connection by means of welding the overlay to the web will ensure the load capacity of the connection.
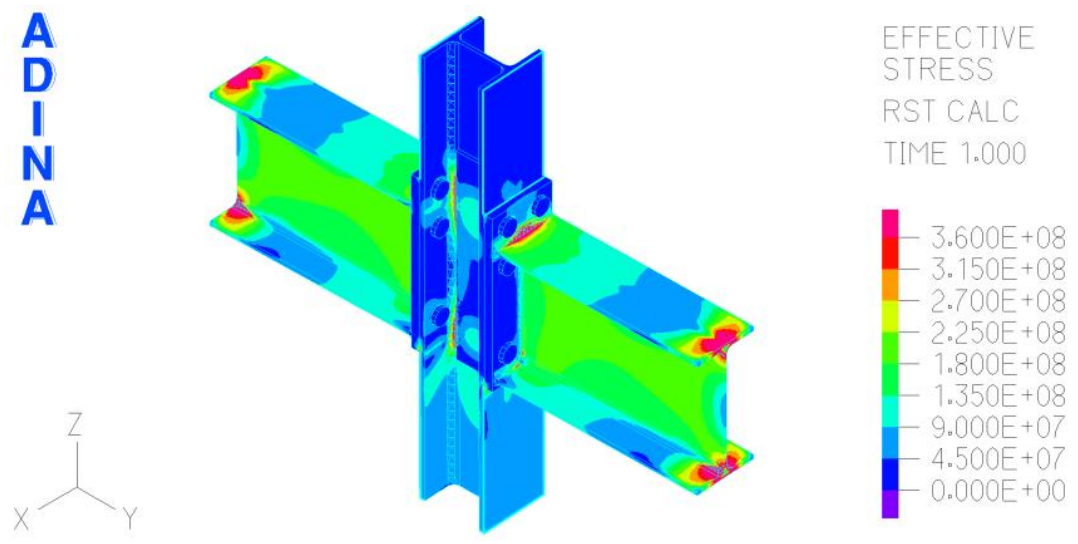

Fig. 6. Analysis stress of reinforcement model with web overlay in the ADINA program.

\section{Conclusion}

The weakest point of connection of double-sided beams with the column is the web panel, which is confirmed by the analyses carried out in this study. With additional ceiling loading, the stress values in the unreinforced column web exceed the allowable values, which involves the need to strengthen the connection. Proposed solutions, such as web reinforced by stiffeners on the extension of the adjacent beam flanges, or welding of a onesided pad to the web result in a significant decrease in stress in the column web (Fig. 7), thus ensuring safe joint. Comparing analytical calculations and numerical analysis, the use of web stiffeners significantly increases the load capacity of the joint than welding the overlay to the column web.
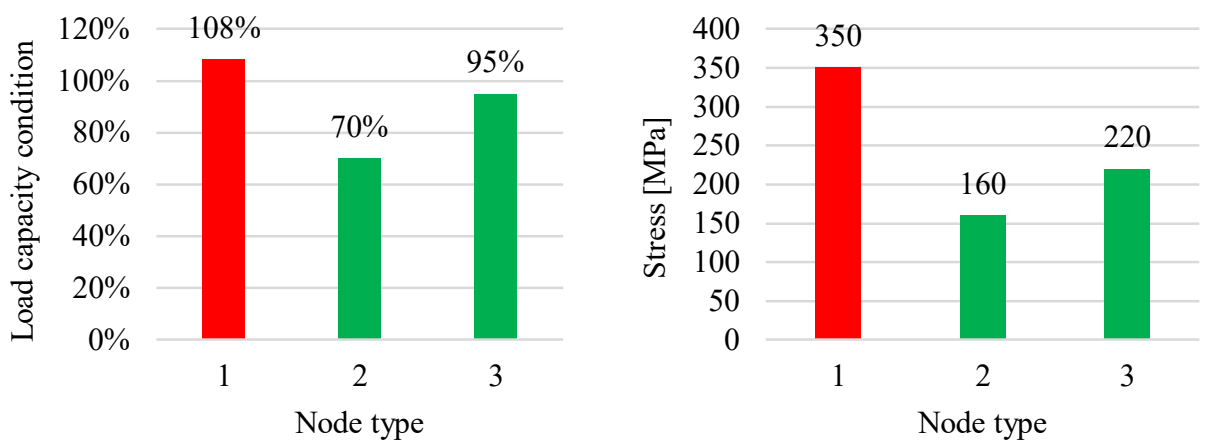

Fig. 7. Values load capacity condition obtained in analytical calculations and stresses in the web of the analysed connection obtained in Adina program: 1 - bolt connection without reinforcements, 2 bolt connection reinforcement with stiffening, 3 - bolt connection reinforcement with an overlay welded on the column web. 


\section{References}

1. A. Kozłowski, Konstrukcje stalowe, Przykłady obliczeń wedtug PN-EN 1993-1 (Oficyna Wydawnicza Politechniki Rzeszowskiej, Rzeszów, 2010) (in polish)

2. J. Bródka, A. Kozłowski, Projektowanie i obliczanie połaczeń $i$ węzłów konstrukcji stalowych (Polskie Wydawnictwo Techniczne, 2009) (in polish)

3. D. A. Nethercot, E. L. Salih, L. Gardner, Proceedings of the 3rd International Forum on Advances in Structural Engineering. 1-18 (2009).

4. PN-EN 1993-1-8 Euro Code 3 Design of steel structure, Design of joints (CEN European Committee for Standardization, 2006) (in polish)

5. R. Yang, X. Zhou, Appl. Mech. Mater. 2019, 1967253 (2019)

6. E. Kormaníková, K. Kotrasová, Appl. Mech. Mater. 617, 247-250 (2014)

7. J. Flodr, P. Kałduński, M. Krejsa, P. Pařenica, Procedia Engineer. 190, 215-222 (2017)

8. E. L. Salih, L. Gardner, D. A. Nethercot, Proceedings of the 9th International Conference on Steel Concrete Composite and Hybrid Structures, 625-632 (2009).

9. P. Helbrych, M. Major, J. Nawrot, Civil and environmental engineering reports, 26, 3, 69-78 (2017)

10. A. Bouchaïr, J. Averseng, A. Abidelah, J. Constr. Steel Res. 64, 11, 1264-1274 (2008).

11. P. M. L. Vilela, H. Carvalho, L. F. Grilo, P. A. Montenegro, R. B. Calçada, Eng. Fail. Anal. 104, 308-320 (2019)

12. M. Major, J. Nawrot, I. Major, IOP Conf. Ser-Mat. Sci. 585, 012007, 6 (2019)

13. H. Yu, I. W. Burgess, J. B. Davison, R. J. Plank, J. Constr. Steel Res. 64, 5, 515-525 (2008)

14. I. Major, M. Major, Z. Respondek, Arch. Metall. Mater. 63, 1, 491-496 (2018)

15. M. Major, K. Kuliński, MATEC Web Conf. 219, 02014, 8, (2018)

16. V. Piluso, G. Rizzano, J. Constr. Steel Res. 64, 6, 655-669 (2008) 